\title{
Light: an indicator of time and place
}

\author{
Michael M. Neff, ${ }^{1,3}$ Christian Fankhauser, ${ }^{1,4}$ and Joanne Chory ${ }^{1,2,5}$ \\ ${ }^{1}$ Plant Biology Laboratory and ${ }^{2}$ The Howard Hughes Medical Institute, The Salk Institute for Biological Studies, \\ La Jolla, California 92037 USA
}

To grow and develop optimally, all organisms need to perceive and process information from both their biotic and abiotic surroundings. A particularly important environmental cue is light, to which organisms respond in many different ways. The responses can be simple, as in phototactic single-celled organisms, or complex, as in higher animals, which use visual inputs to modify their behavior. Many organisms can also detect cycles of light and darkness, which are exploited for seasonal and timeof-day responses.

Because they are both photosynthetic and sessile, plants have to be especially plastic in response to their light environment. In addition to utilizing light as a time-keeping mechanism, plants are unique in that they use light as a source of energy and they analyze light to control such developmental decisions as when to germinate and flower. The diverse responses of plants require sophisticated sensing of intensity, direction, duration, and wavelength of light. The action spectra of light responses have provided assays to identify three photoreceptors absorbing in the ultraviolet, blue/near ultraviolet, and red/far-red (R/FR)-spectral ranges (Kendrick and Kronenberg 1994). The best characterized group of these photoreceptors is the red/far-red (R/FR) absorbing phytochromes. Phytochromes are photochromic proteins composed of a large protein $(\sim 125 \mathrm{kD})$ covalently attached to a linear tetrapyrrole chromophore. Phytochromes are synthesized in a red-light-absorbing form, $\mathrm{Pr}$ $(\lambda \max =660 \mathrm{~nm})$ which, upon exposure to red light, can be phototransformed into a far-red-light-absorbing form, $\operatorname{Pfr}(\lambda \max =730 \mathrm{~nm})$. Upon exposure to far-red light, Pfr is photoconverted to $\operatorname{Pr}$ (Kendrick and Kronenberg 1994). Both Pfr and Pr that has been photocycled have been shown to induce developmental responses (Shinomura et al 2000). Thus, phytochrome acts as a light-controlled developmental switch. Phytochromes have been found in all taxa of lower and higher plants examined (Mathews and Sharrock 1997; Mathews and Donoghue 1999), as well as cyanobacteria (Hughes et al. 1997; Lamparter et al. 1997; Yeh and Lagarias 1997).

Phytochromes control development throughout the

Present addresses: ${ }^{3}$ Department of Biology, Washington University, St. Louis, Missouri 63130 USA; ${ }^{4}$ Molecular Biology Department, Université de Genève, 1211 Genève 4, Switzerland.

${ }^{5}$ Corresponding author.

E-MAIL chory@salk.edu; FAX (858) 558-6379. plant life cycle beginning with seed germination and seedling deetiolation (the transition from growth in the dark to growth in the light). They also control cotyledon/ leaf expansion and stem elongation by regulating cell division and expansion. Phytochromes enable the perception of neighboring plants or shade, and influence the transition to flowering. Because of these profound effects, phytochromes have been studied intensively for $>50$ years. The impact this family of photoreceptors has had on the history of Botany is extensively covered in the book, Pigment of the Imagination (Sage 1992). Many excellent reviews on phytochrome's role in photomorphogenesis have been written recently (Mancinelli 1994; Smith 1995; Fankhauser and Chory 1997; Mustilli and Bowler 1997; Batschauer 1999; Deng and Quail 1999, and references within). In this review we will describe the complexities of phytochrome response pathways and highlight some of the recent accomplishments in elucidating the mechanisms by which phytochromes regulate so many downstream responses. Finally, we will examine the interactions between phytochrome and endogenous developmental programs.

\section{Phytochrome responses}

One of the major goals in phytochrome research has been to understand the signal transduction pathways that lead to altered development. Early in the twentieth century it was shown that a pigment, separate from the activity of photosynthesis, was involved in photoperiod detection and floral induction (Garner and Allard 1920), although the nature of this pigment was not discovered until 30 years later. In the 1950's, phytochrome was characterized as the pigment that controls lettuce (c.v. Grand Rapids) seed germination in red and far-red light (Borthwick et al. 1952). This developmental response is a classic example of phytochrome's control of plant development and is still used today in undergraduate lab courses. Red light stimulates seed germination, but this induction can be inhibited by subsequent exposure to far-red light. The seeds can be cycled through sequential red or far-red light treatments; however, the final germination response is determined solely by the last light treatment. This experiment defined the parameters for purification of a dichromic photoreceptor that was later termed phytochrome for "plant color". Reciprocity, the 
dependence on the total number of photons irrespective of the duration of exposure, is exhibited in this response, indicating the involvement of a first-order chemical reaction. Red/far-red reversibility and reciprocity are the hallmarks of the classic phytochrome responses. This class of phytochrome responses is known as the low fluence responses (LFRs) and has been described in many different plant systems (Mancinelli 1994).

In addition to the control of lettuce seed germination, LFRs also include responses that are transient in nature, such as changes in ion flux, leaf movement, and chloroplast rotation (Haupt and Hader 1994; Roux 1994). Other LFRs include changes in gene expression during deetiolation, stem elongation, leaf expansion, and the transition to flowering (Cosgrove 1994; Vince-Prue 1994). It is important to note that although these responses have been identified as being induced by red light and inhibited by far-red light, plants are not generally exposed to simple monochromatic light. In reality, plants sense the $\mathrm{R} / \mathrm{FR}$ ratio of light in their surroundings and respond accordingly (Fig. 1). Two subsets of LFRs are the end-ofday far-red responses and shade avoidance responses. By detecting the enrichment of far-red light at dusk, the former affects flowering. (Fig. 1B). Shade avoidance is a response to enrichment of far-red light under a leafcanopy or to reflected light from nearby leaves, and is a mechanism for neighbor detection. In both cases, plants respond by elongating stems and increasing the lengthto-width ratio of leaves (Fig. 1C). Because the changes in plant morphology are similar in each case, these responses are often considered together as a single phenomenon. Both responses are controlled by the ratio of $\mathrm{R} / \mathrm{FR}$ and are thought to be one of the most important functions of phytochrome in natural settings (Smith 1994; Smith and Whitelam 1997).

As more phytochrome-mediated processes were discovered, it became clear that there are at least three physiologically distinct modes of phytochrome action. In addition to the R/FR reversible LFRs, there are two other responses: the very-low-fluence responses (VLFRs) and high-irradiance responses (HIRs). These three response modes can be distinguished by the amount of light required, which varies over eight orders of magnitude. In a typical VLFR, plants respond to between 0.1 and $1 \mu \mathrm{mole} / \mathrm{m}^{2}$ of light, whereas the LFRs are typically between 1 and $1000 \mu$ mole $/ \mathrm{m}^{2}$ of light. In the HIRs, plants generally respond to $>1000 \mu$ moles $/ \mathrm{m}^{2}$ of light although it is fluence rate and not total fluence defining these responses (Mancinelli 1994). Reciprocity is not seen for either the VLFRs or the HIRs. Moreover, unlike the LFRs, VLFRs are not reversible by a subsequent pulse of far-red light. Seed germination in response to very low levels of light is a good example of a VLFR (Shinomura et al. 1996), as are some light-induced changes in gene expression (Cerdàn et al. 1997, 1999; Hamazato et al. 1997).

In contrast to the LFRs, HIRs are prevalent primarily in far-red light, even though these conditions should create the presumed inactive form of phytochrome. A wellstudied far-red HIR is the control of seed germination in
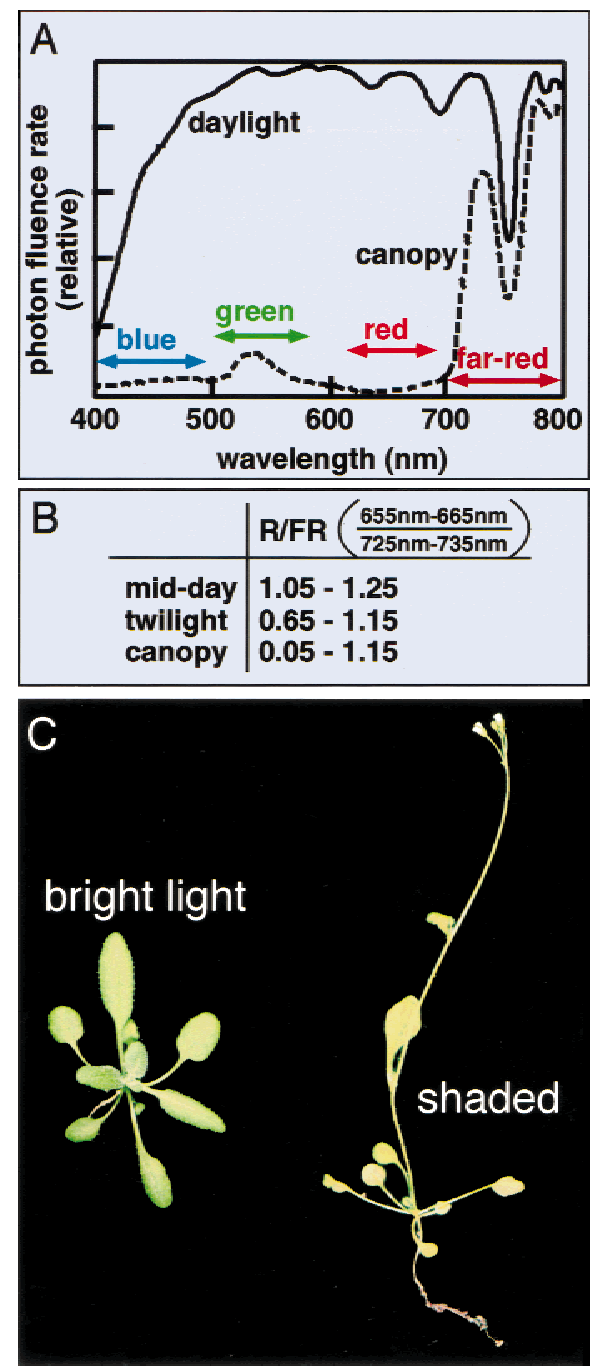

Figure 1. The ratio of R/FR light is a good indicator of time and place. $(A)$ Light spectra of daylight and under a plant canopy. $(B)$ $\mathrm{R} / \mathrm{FR}$ ratios in different times and places. $(C)$ Phenotype of 3-week-old Arabidopsis wild-type (left) and a phyB mutant displaying constitutive shade avoidance (right). Both plants were grown under the same light conditions.

certain plant species. For instance, after imbibition, some Arabidopsis seeds germinate in the dark without an inductive light pulse. This background germination rate varies with the age of seeds and parental growth conditions. Depending on this background germination rate, continuous far-red light can stimulate or inhibit seed germination (Reed et al. 1994; Shinomura et al. 1994). These observations suggest a biological activity for Pr. Because phytochrome null mutants were used in these experiments, it is also possible that multiple pools of phytochromes are acting antagonistically in wild-type seedlings (Whitelam and Devlin 1997). Recent studies from the Furuya laboratory suggest that the far-red HIR requires a short-lived intermediate generated during Pfr to Pr photoconversion (Shinomura et al. 2000). Most interestingly, this response is FR/R reversible (not $\mathrm{R} / \mathrm{FR}$ ), 
which is opposite to what is seen in the LFRs such as far-red inhibition of light-regulated gene expression or lettuce seed germination.

\section{Multiple phytochromes contribute to plant development}

The attribution of the variety of light-regulated responses to a single photoreceptor was one of the problems with early phytochrome research. In the 1980's, spectrophotometric studies indicated that there were at least two distinct pools of phytochrome, type I (Iight labile) and type II (light stable). The light-labile pool degrades fairly rapidly (as fast as a 1-hr half-life, depending on the plant) upon exposure to red or white light. Although there was little spectrophotometrically detectable phytochrome after prolonged exposure to light, $\mathrm{R} / \mathrm{FR}$ responses still persisted. That this stable phytochrome pool had biological activity was demonstrated in seed germination and end-of-day far-red response experiments where the escape times for far-red reversibility were three to four times longer than the degradation times for light-labile phytochrome (for review, see Mancinelli 1994).

The cloning of multiple phytochrome apoprotein genes has shed some light on the distinct pools and modes of action of phytochromes (Abe et al. 1989; Sharrock and Quail 1989). In Arabidopsis, we now know that there are five distinct phytochromes termed phyA-phyE (Sharrock and Quail 1989; Mathews and Sharrock 1997). phyA is a type I phytochrome. phyB-phyE are all type II phytochromes. In dark-grown tissues, phyA is by far the most abundant phytochrome. After exposure to light, the levels of phyA drop up to 100 fold. Degradation of phyA is light dependent and requires selective recognition and ubiquitination of Pfr (Clough et al. 1999). PHYA gene expression is also negatively regulated by light (Somers and Quail 1995a). This repression is rapid, occurs at the transcriptional level, and requires phytochrome (Lissemore and Quail 1988). The regulation of phyA protein level by light is therefore the result of a coordinated transcriptional and post-translational regulation. In light-grown plants, phyB becomes the most abundant phytochrome; phyC-phyE are less abundant type II phytochromes (Clack et al. 1994; Hirschfeld et al. 1998). All five phytochromes are expressed throughout the plant with only minor differences in their expression patterns (Somers and Quail 1995b; Goosey et al. 1997).

Although the presence of multiple phytochromes begins to address the light labile and light stable pools, assigning precise roles in development for each of these photoreceptors required genetic analysis of plants lacking one or more of these pigments. Phytochrome apoprotein mutants have allowed an assessment of the function of individual photoreceptors. phyA and phyB play unique, redundant, or antagonistic roles in different responses throughout Arabidopsis development (Whitelam and Devlin 1997; Cerdàn et al. 1999). phyA is essential for de-etiolation in far-red light (light found under a canopy of plants), whereas phyB is the major red light photoreceptor during seedling development. phyA also mediates responses to very low fluences of blue, red, and far-red light. Mutants in phyD and phyE have more subtle phenotypes, only uncovered in a phyB mutant background, demonstrating a degree of redundancy between phyB, phyD, and phyE, with phyB playing the most prominent role of the three (Aukerman et al. 1997; Devlin et al. 1998, 1999). These three phytochromes play a major role in regulating shade avoidance. No mutations in phyC have been discovered yet, but overexpression studies suggest a role in primary leaf expansion (Halliday et al. 1997; Qin et al. 1997).

In-depth analysis of plants carrying null mutations for different phytochromes has shown that the major phytochrome in Arabidopsis is phyB. Mutations in PHYB have profound effects on plant development throughout the life cycle (Reed et al. 1993). In general, phyB mutant seedlings have long hypocotyls and small cotyledons in continuous red or white light. They also have less anthocyanin, chlorophyll, and fewer chloroplasts than the wild type. As adults, these mutants flower early, have longer petioles and stems, and increased apical dominance. These phenotypes are also observed in mutants with reduced phyB activity from other plant species such as cucumber, pea, tomato, and rape (Whitelam and Devlin 1997). Many of the growth responses regulated by phyB involve cell expansion or elongation. phyB affects nuclear endoreduplication in hypocotyls of Arabidopsis (Gendreau et al. 1998), a possible mode of control of cell size (Gendreau et al. 1997). Generally speaking, phyB mutants show constitutive shade avoidance and are altered in their end-of-day far-red response (Fig. 1C), indicating that it is primarily phyB mediating this process. However, phy $B$ single mutants and phy $A$ phy $B$ double mutants still show responses to reductions in R/FR ratios indicating that other phytochromes play significant roles in plant development (Whitelam and Smith 1991; Robson et al. 1993; Halliday et al. 1994; Devlin et al. 1996). This observation was the basis for the genetic screen that identified phyE mutants (Devlin et al. 1998).

Genetic analysis has shown that there is a complex web of interactions, not only between the phytochromes, but also between phytochromes and the blue light photoreceptors, cryptochromes. A functional dependency of cryptochrome 1 (cryl) on phytochromes has been described based on observations that phyA phyB double mutants have a dramatic blue light phenotype (Ahmad and Cashmore 1997). However, phytochromes can absorb blue light (Furuya and Song 1994). Furthermore, phytochrome mutants have blue light-mediated defects in hypocotyl growth inhibition (Whitelam et al. 1993), cotyledon expansion (Neff and Van Volkenburgh 1994), seed germination (Shinomura et al. 1996), CAB gene induction (Hamazato et al. 1997), and light-induced shrinking of hypocotyl protoplasts (Wang and Iino 1998). Detailed analysis of plants carrying null mutations in multiple phytochromes and cryptochrome argues against a functional dependency of cryptochromes on phytochromes. Rather, these studies demonstrate a complex web of interactions within and between the two 
classes of photoreceptors including redundancy, antagonism, and effector/modulator relationships /Casal and Boccalandro 1995; Casal and Mazzella 1998; Neff and Chory 1998; Wang and Iino 1998; Hennig et al. 1999; Mockler et al. 1999). However, the mechanisms of these interactions are not clear and are subject to debate (Ah$\operatorname{mad} 1999)$.

Effector/modulator relationships describe a situation in which a photoreceptor cannot control a growth response independently yet it can affect that response in the presence of other, controlling, photoreceptors (Mohr 1994). As an example, phototropism is controlled by the blue light-absorbing phototropins, such as NPH1 (Christie et al. 1998), although phytochromes can modulate this response (Parks et al. 1996; Hangarter 1997; Janoudi et al. 1997). Because pretreatments of omnilateral red light can enhance the phototropic response to subsequent exposures of unilateral blue, phytochromes can also act as preprogrammed amplifiers of this phototropin-mediated growth response (Shropshire and Mohr 1970; Woitzik and Mohr 1988). A novel photoreceptor with homology to both phytochrome and NPH1 has recently been isolated from the fern Adiantum (Nozue et al. 1998). In this case, the coaction between blue and red light on phototropism of Adiantum protonema (Hayami et al. 1986) may be acting through a single photoreceptor.

\section{Molecular properties of phytochrome}

One of the major advances made in phytochrome research was the ability to partially purify a species of the pigment, allowing the study of its biochemical properties (Butler et al. 1959, 1964). Because of the pioneering studies of Butler, full-length phyA holoprotein has been purified from multiple plant species. phyA is found as a soluble homodimer with each monomer covalently attached to a linear tetrapyrrole chromophore. Each mono- mer is composed of two domains separated by a small hinge. The spectral properties of phyA have been well characterized because of the relative abundance of this photoreceptor in dark-grown seedlings (Fig. 2A). The cloning of less abundant phytochromes has allowed a comparison between the different family members. When overexpressed in Arabidopsis, phyB displays similar spectral properties to phyA (Wagner et al. 1991). Recombinant phytochromes purified from a variety of sources confirm this view (Gartner et al. 1996; Kunkel et al. 1996; Elich and Chory 1997). However, the use of more sophisticated spectroscopic methods uncovered subtle differences between phyA and phyB, which may account for variation in photoperception in vivo (Remberg et al. 1998).

The chromophore is attached to an invariant cysteine in a well-conserved domain among phytochromes. Light induces an isomerization between rings $\mathrm{C}$ and $\mathrm{D}$ of the tetrapyrrole, accounting for the interchangeable spectral properties of phytochrome. This Pr-to-Pfr transition is accompanied by rearrangements of the protein backbone (Quail 1997). In plants the chromophore is phytochromobilin $(\mathrm{P} \phi \mathrm{B})$, but phycocyanobilin (PCB) will also bind phytochrome resulting in Pr and Pfr spectra that are slightly blue shifted compared with the $\mathrm{P} \phi \mathrm{B}$ adducts (Lagarias and Rapoport 1980). Heme is the starting point for chromophore biosynthesis. Heme oxygenase (HY1 in Arabidopsis) converts heme to billiverdin IX $\alpha$, which is then converted into $3 \mathrm{E}-\mathrm{P} \phi \mathrm{B}$ by $\mathrm{P} \phi \mathrm{B}$ synthase (Davis et al. 1999; Muramoto et al. 1999). The final step of chromophore biosynthesis involves an isomerization leading to $3 Z-\mathrm{P} \phi \mathrm{B}$. Mutants in a number of plant species are incapable of synthesizing 3E- $\mathrm{P} \phi \mathrm{B}$ but the gene encoding P $\phi B$ synthase has not been cloned yet (Terry 1997).

The amino-terminal part of phytochromes is necessary and sufficient for chromophore binding and normal spectral properties. The carboxy-terminal half can be re-
Figure 2. Phytochrome properties are modified by light. (A) Absorption spectra of purified oat phyA in its Pr and Pfr forms. $(B)$ Schematic representation of phytochrome in Pr and Pfr. (NTE) Amino-terminal extension; (CBD) chromophore binding domain; $(\mathrm{P} \phi \mathrm{B})$ phytochromobilin; $(\mathrm{H})$ hinge region; (HKRD1) histidine kinase-related domain 1; (HKRD2) histidine kinase domain 2; $(A, B)$ PAS domains. A number of phytochrome properties affected by light are indicated. Whereas phyB translocates into the nucleus as Pfr, phyA becomes nuclear as both Pfr and photocycled Pr.
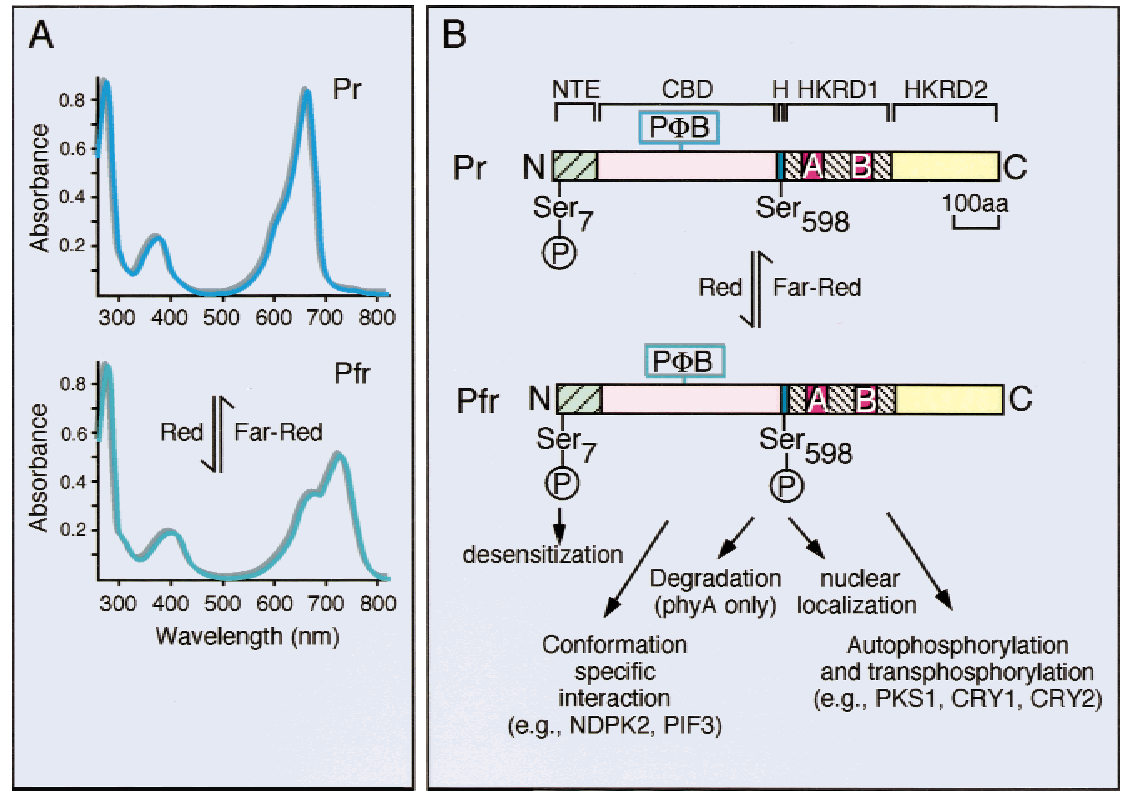
garded as the output domain. This domain appears to be the result of the duplication of a bacterial histidine kinase-related domain (Schneider-Poetsch 1992; Yeh and Lagarias 1998) (Figure 2B). The first of those domains also contains two repeats with homology to PER-ARNT-SIM (PAS) domains (Lagarias et al. 1995; Kay 1997), originally found in basic helix-loop-helix (bHLH) containing transcription factors from fly (PER and SIM) and mammals (ARNT and AHR) (Huang et al. 1993). These modules have been found in a wide variety of organisms and play important signaling roles in protein-protein interactions, response to small ligands, and changes in light conditions, oxygen levels, and redox potential (Taylor and Zhulin 1999). The majority of missense mutations in phyA and phyB cluster in the PAS repeats, demonstrating the importance of this domain for phytochrome function (Quail et al. 1995). One of the phyB missense mutations, phyB-101 (Bradley et al. 1996), is in the second PAS repeat. This mutation affects spectral properties of the pigment, causing accelerated dark reversion from Pfr to Pr, and alters the end-of-day far-red response in seedlings (Elich and Chory 1997). Thus, the PAS repeats may be involved in intramolecular interactions within phytochrome itself.

The discovery of phytochromes in cyanobacteria demonstrates that these proteins are not unique to plants (Kehoe and Grossman 1996). Synechocystis Cph1 (Cyanobacterial phytochrome 1) has spectral properties very similar to the ones of its higher plant relatives (Hughes et al. 1997). Moreover, Cph1 functions as a light-regulated histidine kinase (Yeh et al. 1997) although the biological function of Cph1 in Synechocystis is still unknown. Studies involving prokaryotic phytochromes strongly suggest that plant phytochromes have histidine kinase ancestry. The group of Lagarias has recently shown that two plant phytyochromes are also light and chromophore-regulated protein kinases, but unlike their cyanobacterial counterparts they autophosphorylate on serine/threonine rather than histidine/aspartate (Yeh and Lagarias 1998). Phytochromes are not the first eukaryotic serine/threonine kinases with histidine kinase ancestry (Harris et al. 1997), and much remains to be done to characterize this enzymatic activity. Some important questions to be answered include: What is the catalytic domain of phytochrome kinase? Do different phytochromes, which play distinct roles in vivo, phosphorylate different substrates? And, most importantly, what is the biological relevance of this activity?

Interestingly, phyA isolated from plants is a phosphoprotein with at least one serine phosphorylated in a light-dependent fashion, suggesting that phosphorylation of this residue results from autophosphorylation or from phosphorylation by another phytochrome (Lapko et al. 1999). This serine is also a major phosphoacceptor site identified in in vitro phosphorylation studies (Wong et al. 1986). Residues at the very amino-terminus of phyA are also phosphorylated but not in a light-dependent fashion (Lapko et al. 1997, 1999). However, phosphorylation of this portion of the protein has been implicated in down-regulation of phyA signaling (Stockhaus et al. 1992).

In vitro kinase assays have identified other substrates of phytochrome. Of particular interest are the cryptochrome blue light receptors cry1 and cry2 (Ahmad et al. 1998). Although they are not phosphorylated in a light dependent fashion in vitro, in vivo analysis shows that cry 1 phosphorylation is stimulated by red light. These results are particularly interesting in view of the large body of photobiological evidence suggesting an interaction between phytochrome and the blue light receptors (Mohr 1994). We have recently identified the first phytochrome kinase substrate (PKS1) that is phosphorylated in a light-dependent manner in vitro (Fankhauser et al. 1999). Phosphorylation of PKS1 in vivo also appears to be stimulated by red light, suggesting that phytochrome is the kinase. PKS1 was identified as a protein that binds to the carboxyl-terminus of phyA; it also interacts with the carboxyl-terminus of phyB. The phenotypes of plants overexpressing PKS1 are consistent with PKS1 being a negative regulator of phyB signaling. Fusions with the jellyfish green fluorescent protein (GFP) (Chiu et al. 1996) show that PKS1 is a cytoplasmic protein (Fankhauser et al. 1999). It will be important to assess the relevance of cry1, cry2, and PKS1 phosphorylation in phytochrome signaling. Figure $2 \mathrm{~B}$ presents some of the ways this kinase activity may affect phytochrome signal transduction.

Another property of phytochrome that is affected by light is its subcellular localization. Immunolocalization of phyA performed mainly in dark-grown tissues indicated that phyA is predominantly a cytoplasmic protein (Pratt 1994). However, this view was challenged a few years ago when it was found that a significant portion of the total phyB is present in the nucleus of light-grown plants (Sakamoto and Nagatani 1996). These results have recently been confirmed and extended with both phyAGFP and phyB-GFP fusion proteins (Kircher et al. 1999; Yamaguchi et al. 1999). Both phyA and phyB are cytoplasmic when plants are kept in the dark but exposure to light triggers the translocation of these photoreceptors to the nucleus (Fig. 3) (Kircher et al. 1999; Yamaguchi et al. 1999|. Interestingly, the fusion proteins form speckles in the nucleus (Kircher et al. 1999; Yamaguchi et al. 1999), similar to the structures that factors involved in RNA transcription and processing form in animal cells (Lamond and Earnshaw 1998). COP1, a negative regulator of photomorphogenesis, is also found in nuclear speckles (Ang et al. 1998). This raises the possibility that phytochromes are found in a large complex in the nucleus. However, it should be noted that each of these GFP fusion proteins were expressed from strong constitutive promoters, and it is possible that the speckles in the nucleus are artifacts of overexpression. These speckles are not seen when phy A-GFP is driven by the endogenous phy $A$ promoter (Fig. 3), even though the fusion protein is nuclear localized and capable of rescuing a phyA-null mutant (C. Fankhauser and J. Chory, unpubl.).

The kinetics and light requirements for phyA and phyB nuclear translocation are quite different. Under- 

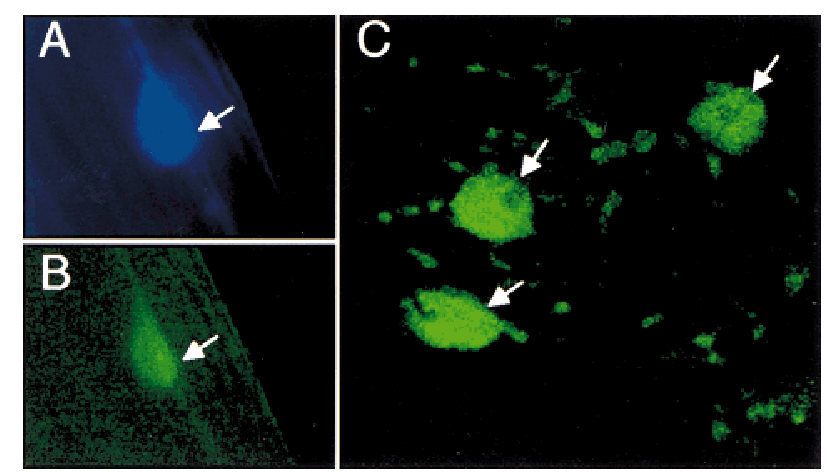

Figure 3. Nuclear localization of phyA-GFP in Arabidopsis seedlings exposed briefly to light. Arrows indicate the nuclei. (A) DAPI staining in a hypocotyl cell; $(B)$ GFP fluorescence of the same cell; $(C)$ GFP fluorescence of a confocal section in the hypocotyl. Three nuclei are clearly visible; the smaller structures are plastids that autofluoresce under the wavelengths used to excite GFP.

standing this difference might explain part of the different modes of action of phyA and phyB (Kircher et al. 1999). For phyB there is good evidence that nuclear translocation occurs only in the Pfr conformation. Phytochrome binding to the nonphotoconverting chromophore, phycoerythrobilin, results in brightly orange fluorescent adducts. Under these conditions, phyA remains cytoplasmic-reminiscent of dark-grown seedlings-indicating that photoconversion of the chromophore is required for nuclear translocation of phyA (Murphy and Lagarias 1997). However, phyA migrates into the nucleus even in far-red light (Kircher et al. 1999), suggesting that phyA in its Pr configuration is capable of nuclear accumulation if it has been cycled through Pfr. It is worth pointing out that the light-induced Pr-to-Pfr transformation is very rapid; however, phyB takes several hours to accumulate to significant levels in the nucleus. Thus, the Pfr form of phyB must be present in both the cytoplasmic and nuclear compartments (Kircher et al. 1999; Yamaguchi et al. 1999). Moreover, many phytochrome responses, such as membrane depolarization or changes in hypocotyl growth rates, occur within minutes of irradiation with light (Cosgrove 1994). It is therefore likely that the nucleus is not the only site of action of phytochromes.

\section{Phytochrome signaling components}

Four major approaches have been used to identify early signaling components downstream of phytochrome. Physiological approaches have been taken to identify rapid responses associated with phytochrome activity. Pharmacological approaches involved microinjection of possible second messengers into phytochrome mutants of tomato. Molecular approaches identified phytochromeinteracting components using two-hybrid screens in yeast. Finally, genetic approaches focused on the isolation of signaling mutants in Arabidopsis.
One of the most rapid physiological actions of phytochrome is its effect on ion fluxes at the plasmamembrane (for review, see Racusen and Galston 1983; Blatt 1987; Kendrick and Bossen 1987). The first demonstration of this effect was the red/far red-reversible electrostatic adhesion of etiolated roots to phosphate-treated glass (Tanada 1967, 1968; Yunghans and Jaffe 1970). In these and other etiolated tissues, phytochrome is directly involved in rapid changes of the membrane potential that occur upon exposure to light (Racusen and Galston 1983). On the other hand, the role of phytochrome in the light-induced electrical responses of green plant cells is less certain. Although these light-induced electrical responses have been shown to depend on the presence of chloroplasts (Tazawa and Shimmen 1980) and full functioning of photosynthesis (Spalding and Goldsmith 1993), there are also reports that demonstrate a direct involvement of phytochrome in the electric responses of green plant cells to light. These include chloroplast movement and ion flux in the green alga Mougeotia (Serlin and Roux 1984; Serlin et al. 1996), ion fluxes in the green alga Nitella (Weisenseel and Ruppert 1977), and ion fluxes associated with branching in the moss Physcomitrella (Ermolayeva et al. 1996, 1997). Experiments with inhibitors and external calcium levels demonstrated that calcium participates in many of these responses as well as in fern spore germination in Dryopteris (Wayne and Hepler 1984) and red light-induced swelling of etiolated wheat leaf protoplasts (Tretyn et al. 1990; Shacklock et al. 1992).

The pharmacological approach has identified heterotrimeric G proteins, cGMP, and calcium as being early components in phytochrome signaling (for review, see Mustilli and Bowler 1997). These second messengers induce chlorophyll and anthocyanin biosynthesis in addition to many light-regulated genes such as FNR (encoding a ferredoxin $\mathrm{NADP}^{+}$oxidoreductase), CHS (encoding chalcone synthase), and $C A B$ (encoding chlorophyll a,b-binding proteins) (Neuhaus et al. 1993; Bowler et al. 1994). In addition, these same pathways can repress the AS1 gene (encoding asparagine synthase) (Neuhaus et al. 1997). Although a role for changes in ion transport across the plasma membrane and second messengers in light mediated signal transduction is apparent, the connection between these responses and specific gene products has not yet been made.

Yeast two-hybrid screens were used to identify PKS1 as a phytochrome-interacting protein. Two other interacting components have been identified in yeast twohybrid screens. One of these, nucleoside diphosphate kinase 2 (NDPK2) was identified in a screen for proteins interacting with the carboxyl terminus of phyA (Choi et al. 1999). The activity of NDPK2 but not NDPK1 (which does not interact with phytochrome) was shown to increase dramatically when interacting with the Pfr form of phyA. In both the PKS1 and NDPK2 two-hybrid screens, phyA itself was identified as one of the interacting partners with phyA. Given that phytochromes are dimers, this argues that these screens are valid and capable of identifying bona fide phyA interacting partners. 
Plants overexpressing PKS1 have longer hypocotyls in red light, suggesting that PKS1 is a negative regulator of hypocotyl elongation downstream of phyB. In contrast, NDPK2 appears to be a positive regulator of phyA and phyB signaling. However, hypocotyl elongation is not affected by this regulatory component. Instead, loss-offunction alleles have a small but significant reduction in cotyledon greening and opening of the hypocotyl/cotyledon hook during deetiolation (Choi et al. 1999).

ndpk2 mutants have altered responses to both red and far-red light, suggesting that this regulator interacts in vivo with both phyA and phyB. NDPK2-GFP fusions expressed in tobacco show both cytoplasmic and nuclear localization. Thus, phytochrome may interact with NDPK2 in both the cytoplasm and the nucleus. Red light has been shown to stimulate phosphorylation of NDPK2 in vivo suggesting that this interacting protein may also be a substrate for phytochrome kinase activity (Hamada et al. 1996; Tanaka et al. 1998; Ogura et al. 1999). The PAS domains in phytochrome are clearly important as NDPK2 does not interact with a phyA mutated in one of the two PAS repeats. The mechanism of action for NDPK2 in plants is not known although studies in other model systems implicate this enzyme in many developmental processes (Tanaka et al. 1998; Choi et al. 1999).

A third phytochrome-interacting partner is PIF3, a nuclear-localized, putative bHLH-containing transcription factor isolated by virtue of its binding to both phyA and phyB in the yeast two-hybrid system. Decreasing PIF3 levels results in plants that are defective in both red and far-red light sensing, consistent with the view that this gene acts downstream of both photoreceptors (Ni et al. 1998). Importantly, PIF3 binds phyB in a light-dependent fashion (Ni et al. 1999). As with NDPK2, PIF3 does not interact with phytochromes mutated in the PAS domain. These results again underscore the importance of the PAS domain in phytochrome signaling because mutations in the PAS domain have major effects on both its spectral properties (Elich and Chory 1997) and its ability to interact with downstream signaling partners. It will be important to test if PIF3 is modified in response to light, or if binding to phytochrome directly modulates the activity of this putative transcription factor. For example, the activity of CCA1, a DNA-binding protein acting downstream of phytochromes, can be modulated by phosphorylation (Sugano et al. 1998). However, casein kinase 2, but not phytochrome, appears to be the protein kinase mediating CCA1 phosphorylation.

Genetic and molecular screens have identified a large number of genes acting downstream of light receptors. Because different light qualities trigger the same developmental responses using different photoreceptors, it is very likely that common late-acting signaling intermediates are used. Mutants in such genes are expected to have the same phenotypes irrespective of the light quality. Such loci have been identified and they fall into two classes: mutants that deetiolate even in the absence of light and mutants that are defective for their perception of light at a variety of different wavelengths. The former class is referred to as det/cop/fus mutants based on the different genetic screens from which they were isolated. These are pleiotropic mutations affecting many aspects of plant development and these proteins are generally considered to be late signaling components (for review, see Fankhauser and Chory 1997; Deng and Quail 1999; Osterlund et al. 1999; Wei and Deng 1999).

Early signaling intermediates are expected to have a phenotype only under the specific light conditions activating their photoreceptor (Fig. 4). Such mutants can be further classified into genes that affect phyA signaling (defective in far-red light), phyB signaling (defective in red light) or both phyA and phyB signaling (defective in red and far-red light perception). FHY1, FHY3, FIN2, SPA1, and FAR1 are implicated specifically in phyA signaling. Genetic analysis suggests that, except for SPA1, they all act as positive elements in this pathway (Whitelam et al. 1993; Hoecker et al. 1998; Soh et al. 1998; Hudson et al. 1999). spa1 was identified as a suppressor of a weak phyA mutation, and mutations in this gene increase the "signaling current" in a phyA-dependent manner (Hoecker et al. 1998). The gene codes for a putative protein with a carboxy-terminal domain related to the negative regulator of photomorphogenesis COP1 (Hoecker et al. 1999). far1 was identified in a screen for suppressors of the exaggerated light response of phyA overexpressing plants. FAR1 is a member of a small gene family in Arabidopsis; homologous sequences can also be identified in other plant species (Hudson et al. 1999). Both SPA1 and FAR1 are localized in the nucleus as determined by transient expression of GUS fusion proteins. It is currently unknown whether this localization is con-

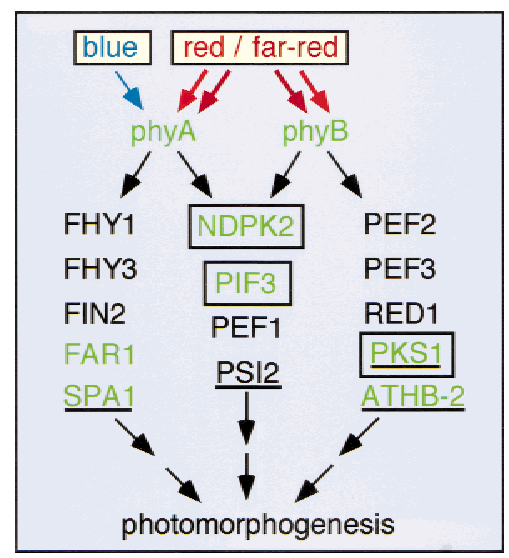

Figure 4. Early intermediates in phytochrome signaling. Cloned genes are indicated in green. Negative regulators are underlined. Proteins that interact with phytochrome are boxed. Not all cloned genes have been tested for physical interaction with phytochrome. This diagram does not imply that all those genes act downstream of the photoreceptors but simply indicates that they affect a specific branch of phy signaling. PKS1 interacts both with phyA and phyB but appears to inhibit phyB signaling. Multiple phytochromes affect ATHB-2 expression, but ATHB-2 acts as a negative regulator of type II phytochromes (phyB). We have indicated only phyA and phyB here; some of those genes could also regulate phyC, phyD, and/or phyE signaling. 
stitutive or regulated by light. A number of earlier studies have suggested that phytochrome signaling involves light-regulated protein phosphorylation (Roux 1994). Now that we know that phytochrome itself is a protein kinase, and that a number of downstream acting factors have been identified, it is important to test if these proteins directly interact with phyA and if they are substrates for phyA's protein kinase activity.

red1, pef2, and pef3 are in a class of mutants specifically affected in red light signaling. They share a number of features with phyB mutants, such as early flowering in short days, elongated petioles, and decreased sensitivity to red light (Reed et al. 1993; Ahmad and Cashmore 1996; Wagner et al. 1997). The molecular nature of these genes will certainly provide us with new insights into phyB signaling. The poc1 mutant shows exaggerated response to red light. This phenotype is caused by a $\mathrm{T}$ DNA insertion, causing the overexpression of the gene encoding PIF3. Although PIF3 interacts with both phyA and phyB, light-grown poc1 mutants do not show enhanced responses to far-red light (Halliday et al. 1999). PKS1 could also be classified in this group but unlike the above-mentioned genes, PKS1 appears to act as a negative regulator of phyB signaling (Fankhauser et al. 1999). Another mediator of type II phytochrome responses is the homeodomain leucine zipper protein HAT4/ ATHB-2 (Schena et al. 1993; Steindler et al. 1999). This transcription factor plays an important role in shade avoidance responses (Steindler et al. 1999). The expression of this gene is regulated by $\mathrm{R} / \mathrm{FR}$ ratios, and an elegant series of studies indicate that ATHB-2 acts as a negative regulator of gene expression (Carabelli et al. 1996; Steindler et al. 1999|. pef1 and psi2 mutants are affected in both phyA and phyB signaling. The former is less sensitive to red and far-red light, whereas the latter is hypersensitive to such light treatments (Ahmad and Cashmore 1996; Genoud et al. 1998). As NDPK2 loss-offunction mutants are less responsive to both red and farred light, they can also be included in this class downstream of both phyA and phyB (Choi et al. 1999).

\section{Models for phytochrome signaling}

We are now beginning to develop the tools necessary to model the early mechanisms of phytochrome signal transduction. Light has numerous effects on phytochrome, including changes in both its spectral properties and the overall conformation of the protein (Fig. 2B). In turn, these conformational changes influence the subcellular localization, stability (in the case of phyA), as well as the protein kinase activity of phytochrome. As phytochrome autophosphorylation is light dependent, this post-transcriptional modification could be a direct link between the light conditions and the photoreceptor's subcellular localization, stability, and interaction with signaling partners. The transphosphorylation activity of phytochrome is also regulated by light, allowing lightdependent modification of other signaling components as well (Fig. 2B). One possible model is that phytochromes, in their Pr form, may interact with cytoplas- mic proteins such as PKS1. Upon exposure to light, phosphorylation of PKS1 by phytochrome may release phytochrome from PKS1, allowing nuclear translocation of phytochrome. Once in the nucleus, phytochrome could interact with nuclear proteins such as PIF3, thus regulating the transcriptional activity of late signal transduction components or genes directly involved in growth responses. In certain cell types, phytochrome may require additional regulatory factors that could be both cytoplasmic and nuclear, such as NDPK2.

A model in which Pr is inactive and Pfr is the active form of phytochrome is compatible with the VLFR and LFR modes of phytochrome action; however this does not explain the phyA-mediated HIR. The photocycling of phyA into the Pr form appears to be responsible for the HIR-, however this is not the same $\mathrm{Pr}$ as de novo synthesized phyA that has never seen light (not photocycled) (Shinomura et al. 2000). One could therefore imagine that these two forms of Pr have different posttranscriptional modifications. Because phyA autophosphorylation is light regulated, we propose that additional phosphates could be the difference between $\mathrm{Pr}$ and cycled Pr (Yeh and Lagarias 1998; Lapko et al. 1999). This cycled Pr would be active and short lived because one must constantly supply the plant with new photocycled Pr to obtain a sustained response (Shinomura et al. 2000). A model in which both Pfr and cycled Pr is translocated to the nucleus would explain how phyA accumulates in the nucleus after either red or far-red light treatments.

Light-induced, conformation-specific binding of a photoreceptor to a transcription factor is a very attractive model for phytochrome signaling (Smith 1999). Interestingly, earlier studies have suggested that phytochrome signaling involves phosphorylation of nuclear proteins (Roux 1994). Moreover, the activity of a number of transcription factors is regulated by phosphorylation (Komeili and O'Shea 1999). Although this simple model is attractive, attributing this type of model to all of phytochrome signaling is risky. The myriad of phytochrome responses and complexity of interplay between the different species of photoreceptor within the plant point to a more complex, global regulation of phytochrome signal transduction. Perhaps each phytochrome pool controls only a subset of plant developmental responses. Mutations in PKS1, PIF3, and NDPK2 each have unique phenotypes affecting different tissues in the seedling. It is certainly possible that these components interact with phytochrome only in certain cell types with PKS1 and PIF3 being active in the hypocotyl and NDPK2 active in cells of the hook region. In addition, there are many phytochrome responses, such as changes in ionic conductance across the plasmamembrane that occur faster than the rate of nuclear translocation or activation of transcription. Thus, it is likely that phytochrome acts in other cellular compartments in addition to the nucleus.

\section{Integrating phytochrome signaling with whole plant development}

In addition to light, many plant hormones contribute to 
photomorphogenic responses. This is not surprising because the two classes of signals act on similar cells and organs. Cell expansion is one phenomenon that can be affected dramatically by both light and hormones. The quality and quantity of light can both inhibit and induce stem elongation (Chory 1997; Smith and Whitelam 1997). Likewise, phytohormones also affect stem elongation. In most cases ethylene, abscisic acid, and cytokinins inhibit cell elongation. In contrast, brassinosteroids, gibberellins, and auxin can increase cell elongation (Chory et al. 1994; Creelman and Mullet 1997; Kende and Zeevart 1997; McGrath and Ecker 1998). Some photomorphogenetic mutants resemble mutants involved in phytohormone biosynthesis or sensing. For example, the gibberellin (GA) signaling mutant spindly resembles mutations in phyB with long stems, pale leaves and early flowering, a phenotype that can also be mimicked in wild-type plants by the application of $\mathrm{GA}_{3}$ (Jacobsen and Olszewski 1993). Genetic analysis of GA and phytochrome mutants points to interactions between these two signal transduction systems for certain responses (Chory and Li 1997) although other responses, such as flowering, are likely to be controlled independently by both systems (Blázquez and Weigel 1999). Phytochromes can regulate the transcription of GA biosynthesis genes (Kamiya and García-Martínez 1999). This may be one of the mechanisms of interaction between these two signaling systems and is likely to be involved in phyB's role in generating a graft-transmissible substance that controls tuber formation in potato (Jackson et al. 1996, 1998; Kamiya and García-Martínez 1999).

Many brassinosteroid mutants have been identified in genetic screens for plants which can undergo deetiolation in the absence of a light cue (for review, see Clouse and Sasse 1998; Li and Chory 1999). When these mutants are grown in the dark, their seedlings have short hypocotyls with cotyledons that begin to develop as if growing in the light. As adults these mutants are dwarfs with dark green epinastic leaves, have short stems and petioles, and are slow growing with delayed senescence. Each of these adult phenotypes is essentially the opposite of mutants lacking phytochrome B (Chory and Li 1997; Kamiya and García-Martínez 1999). Although these mutants were identified in photomorphogenetic screens, it has been a challenge to describe the molecular mechanism of interaction between photoreceptor and brassinosteroid signaling pathways. Light does not appear to regulate the activity of brassinosteroid biosynthetic genes or the putative receptor. In fact, these genes have similar, ubiquitous expression throughout the plant. In a screen for extragenic, dominant, gain-of-function suppressors of a phyB missense mutation (phyB-4; Koornneef et al. 1980; Reed et al. 1993), we have identified a cytochrome P450, called BAS1, that catalyzes the inactivation/degradation of brassinosteroids (Neff et al. 1999). Overexpression of BAS1 results in dwarf plants that cannot undergo the shade avoidance syndrome seen in phyB mutants. Genetic analysis characterizes this dominant mutation in BAS1 as a bypass suppressor of phy $B$ acting downstream of phyA and cryl. Although it is unknown how photoreceptors regulate the activity of BAS1, this work demonstrates an interaction between multiple photoreceptors and brassinosteroid catabolism (Neff et al. 1999).

Both physiological and genetic studies indicate a role for auxins in photomorphogenesis. Auxin transport is affected in a light-dependent manner (Jensen et al. 1998). Moreover, HY5, mutations in which result in seedlings with long hypocotyls in varying light conditions (Koornneef et al. 1980), encodes a bZIP transcription factor that may be involved in auxin signaling (Oyama et al. 1997). Transgenic plants or mutants with elevated auxin levels also confer seedling phenotypes associated with photomorphogenesis. Although evidence for direct interactions between these signaling pathways is lacking, the possibility for overlap between these two developmental regulation systems is evident (Boerjan et al. 1995; Romano et al. 1995). One possible mechanism is brought forth in studies linking the hightemperature promotion of hypocotyl elongation with elevated levels of free auxins (Gray et al. 1998). An additional link between auxin signaling and photomorphogenesis is found in the cloning of SHY2. shy2 was identified as a suppressor of the long-hypocotyl phenotype found in mutants with reduced levels of all phytochromes (Kim et al. 1998) or a null allele of phyB (Reed et al. 1998). This dominant mutation resides in the auxin-induced gene IAA3 (Tian and Reed 1999). The most recent evidence for interactions between phytochrome and auxin signaling pathways comes from further analysis of the negative regulator ATHB-2, a transcription factor whose expression is regulated in response to far-red-enriched light. ATHB-2-overexpressing plants confer a shade avoidance phenotype that is in part due to interference with auxin transport or sensing mechanisms (Steindler et al. 1999).

In addition to interactions with phytohormones, phytochromes also effect the activity of the circadian clock (Millar et al. 1995). In studies of the circadian expression pattern of the light-induced $C A B 2$ gene, phyA and phyB both affect the acute light response in etiolated seedlings though they have little effect on the expression pattern in green seedlings grown in a 12-hr light/dark cycles (Anderson et al. 1997). When phyA or phyB mutants are entrained by a circadian light cue then exposed to varying intensities of continuous red light, a role for these photoreceptors is uncovered. phyA shortens the clock period in response to low fluence red light whereas phyB shortens the period of the clock in response to high fluence red light (Somers et al. 1998). Studies using a phyB mutant in Sorghum bicolor show that phyB is involved in the circadian control of ethylene production. Though phyB does not directly affect the clock oscillator, it does modulate this response most likely through a shade avoidance mechanism (Finlayson et al. 1998, 1999). The mechanism by which phytochromes affect circadian rhythms is unknown. However, it is clear that many mutants with aberrant circadian functions also confer seedling phenotypes linking them with photomorphogenesis (Hicks et al. 1996; Schaffer et al. 1998; Wang and 
Tobin 1998; Dowson-Day and Millar 1999; Sugano et al. 1999).

\section{Technology transfer to crops}

It is a complex web of molecular and cellular interactions that finally control developmental events such as cell division, expansion, and differentiation. Identification of the components that act at the nodes of interaction between multiple signaling pathways may impact our ability to modify horticultural and agricultural crops (Robson and Smith 1997). For example, overexpression of oat phyA in transgenic tobacco greatly improved the harvest index (Robson et al. 1996) by alleviating some of the shade avoidance response created by close planting. Similarly, when Arabidopsis phyB is overexpressed in potato, photosynthetic performance and life span are increased, leading to higher tuber yield (Thiele et al. 1999). Overexpression of oat phyA in hybrid aspen increases dwarfism and reduces shade avoidance (Olsen et al. 1997) possibly allowing for closer crop spacing and increased wood production per area.

Despite these promising gains, the effects of altering photoreceptor expression may not be the best way to manipulate crops. For instance, although the number of tubers is increased in potatoes overexpressing phyB, the tuber size is smaller (Thiele et al. 1999). Hybrid aspen overexpressing phyA have lost the ability to acclimate to cold temperatures due to a lack of end-of-day far-red responses, making them more susceptible to frost /Olsen et al. 1997). However, by cloning and modifying downstream genes that affect a subset of phytochrome-mediated output traits, we should be able to develop a more fine tuned control over altering developmental traits in response to light.

One way to clone and control the activity of photomorphogenesis output genes utilizes high throughput studies of phytochrome-mediated gene expression. A recent paper utilized fluorescence differential display to identify 20 differentially expressed genes between wild type and a phyA-null mutant (Kuno et al. 2000). These techniques, coupled with the saturated screening of phytochrome interacting partners and continued identification and cloning of mutations involved in photomorphogenesis, will give us a large genetic tool box. By expanding these approaches to the more primitive phytochrome signaling pathways found in lower plants and bacteria, we may identify components with novel actions in higher plants. With these tools we may be able to manipulate crop production and gain fundamental insight into the complex interactions of phytochrome signaling pathways with other regulatory systems in plants.

\section{Acknowledgments}

We thank Leslie Barden for help with the figures, and Tedd Elich for inspiring the title. Work on photomorphogenesis in our laboratory is supported by grants from the National Institutes of Health, (NIH), National Science Foundation, U.S. Department of Agriculture, and the Howard Hughes Medical Institute. J.C. is an Associate Investigator of the Howard Hughes Medical Institute; M.M.N. was supported by a fellowship from the NIH, and C.F. was supported by fellowships from the Human Frontiers Science Program and the Swiss National Science Fund.

\section{References}

Abe, H., K. Takio, K. Titani, and M. Furuya. 1989. Amino-terminal amino acid sequences of pea phytochrome II fragments obtained by limited proteolysis. Plant Cell Physiol. 30: 1089-1097.

Ahmad, M. 1999. Seeing the world in red and blue: insight into plant vision and photoreceptors. Curr. Opin. Plant. Biol. 2: 230-235.

Ahmad, M. and A.R. Cashmore. 1996. The pef mutants of Arabidopsis thaliana define lesions early in the phytochrome signaling pathway. Plant J. 10: 1103-1110.

- 1997. The blue-light receptor cryptochrome 1 shows functional dependence on phytochrome A or phytochrome B in Arabidopsis thaliana. Plant J. 11: 421-427.

Ahmad, M., J.A. Jarillo, O. Smirnova, and A.R. Cashmore. 1998. The CRY1 blue light photoreceptor of Arabidopsis interacts with phytochrome A in vitro. Mol. Cell 1: 939-948.

Anderson, S.L., D.E. Somers, A.J. Millar, K. Hanson, J. Chory, and S.A. Kay. 1997. Attenuation of phytochrome A and B signaling pathways by the Arabidopsis circadian clock. Plant Cell 9: 1727-1743.

Ang, L.H., S. Chattopadhyay, N. Wei, T. Oyama, K. Okada, A. Batschauer, and X.-W. Deng. 1998. Molecular interaction between COP1 and HY5 defines a regulatory switch for light control of Arabidopsis development. Mol. Cell 1: 213-222.

Aukerman, M.J., M. Hirschfeld, L. Wester, M. Weaver, T. Clack, R.M. Amasino, and R.A. Sharrock. 1997. A deletion in the PHYD gene of the Arabidopsis Wassilewskija ecotype defines a role for phytochrome D in red/far-red light sensing. Plant Cell 9: 1317-1326.

Batschauer, A. 1999. Light perception in higher plants. Cell Mol. Life Sci. 55: 153-166.

Blatt, M.R. 1987. Yearly review: Toward the link between membrane transport and photoreception in plants. Photochem. Photobiol. 45: 933-938.

Blázquez, M.A. and D. Weigel. 1999. Independent regulation of flowering by phytochrome B and gibberellins in Arabidopsis. Plant Physiol. 120: 1025-1032.

Boerjan, W., M.T. Cervera, M. Delarue, T. Beeckman, W. Dewitte, C. Bellini, M. Caboche, H. Van Onckelen, M. Van Montagu, and D. Inze. 1995. Superroot, a recessive mutation in Arabidopsis, confers auxin overproduction. Plant Cell 7: 1405-1419.

Borthwick, H.A., S.B. Hendricks, M.W. Parker, E.H. Toole, and V.K. Toole. 1952. A reversible photoreaction controlling seed germination. Proc. Natl. Acad. Sci. 38: 662-666.

Bowler, C., G. Neuhaus, H. Yamagata, and N.-H. Chua. 1994. Cyclic GMP and calcium mediate phytochrome phototransduction. Cell 77: 73-81.

Bradley, J.M., G.P. Murphy, G.C. Whitelam, and N.P. Harberd. 1996. Identification of phytochrome B amino acid residues mutated in three new phyB mutants of Arabidopsis thaliana. J. Exp. Bot. 47: 1449-1455.

Butler, W.L., K.H. Norris, H.W. Siegelman, and S.B. Hendricks. 1959. Detection, assay, and preliminary purification of the pigment controlling photoresponsive development of plants. Proc. Natl. Acad. Sci. 45: 1703-1708.

Butler, W.L., S.B. Hendricks, and H.W. Siegelman. 1964. Action spectra of phytochrome in vitro. Photochem. Photobiol. 3: 
$521-528$.

Carabelli, M., G. Morelli, G. Whitelam, and I. Ruberti. 1996. Twilight-zone and canopy shade induction of the Athb-2 homeobox gene in green plants. Proc. Natl. Acad. Sci. 93: 3530-3535.

Casal, J.J. and H. Boccalandro. 1995. Co-action between phytochrome B and HY4 in Arabidopsis thaliana. Planta 197: 213-218.

Casal, J.J. and M.A. Mazzella. 1998. Conditional synergism between cryptochrome 1 and phytochrome $\mathrm{B}$ is shown by the analysis of phy $A, p h y B$, and hy 4 single, double, and triple mutants in Arabidopsis. Plant Physiol. 118: 19-25.

Cerdàn, P.D., R.J. Staneloni, J.J. Casal, and R.A. Sánchez. 1997. A 146 bp fragment of the tobacco $L h c b 1^{*} 2$ promoter confers very-low-fluence, low-fluence and high-irradiance responses of phytochrome to a minimal CaMV 35 S promoter. Plant Mol. Biol. 33: 245-255.

Cerdàn, P.D., M.J. Yanovsky, F.C. Reymundo, A. Nagatani, R.J. Staneloni, G.C. Whitelam, and J.J. Casal. 1999. Regulation of phytochrome B signaling by phytochrome A and FHY1 in Arabidopsis thaliana. Plant J. 18: 499-507.

Chiu, W.-I., Y. Niwa, W. Zeng, T. Hirano, H. Kobayashi, and J. Sheen. 1996. Engineered GFP as a vital reporter in plants. Curr. Biol. 6: 325-330.

Choi, G., H. Yi, J. Lee, Y.K. Kwon, M.S. Soh, B. Shin, Z. Luka, T.R. Hahn, and P.S. Song. 1999. Phytochrome signalling is mediated through nucleoside diphosphate kinase 2. Nature 401: 610-613.

Chory, J. 1997. Light modulation of vegetative development. Plant Cell 9: 1225-1234.

Chory, J. and J. Li. 1997. Gibberellins, brassinosteroids and light-regulated development. Plant Cell Environ. 20: 801806.

Chory, J., D. Reinecke, S. Sim, T. Washburn, and M. Brenner. 1994. A role for cytokinins in de-etiolation in Arabidopsis: det mutants may have an altered response to cytokinins. Plant Physiol. 104: 339-347.

Christie, J.M., P. Reymond, G.K. Powell, P. Bernasconi, A.A. Raibekas, E. Liscum, and W.R. Briggs. 1998. Arabidopsis NPH1: A flavoprotein with the properties of a photoreceptor for phototropism. Science 282: 1698-1701.

Clack, T., S. Mathews, and R.A. Sharrock. 1994. The phytochrome apoprotein family in Arabidopsis is encoded by five genes: The sequences and expression of PHYD and PHYE. Plant Mol. Biol. 25: 413-427.

Clough, R.C., E.T. Jordan-Beebe, K.N. Lohman, J.M. Marita, J.M. Walker, C. Gatz, and R.D. Vierstra. 1999. Sequences within both the $\mathrm{N}$ - and C-terminal domains of phytochrome A are required for Pfr ubiquitination and degradation. Plant J. 17: 155-167.

Clouse, S. and J. Sasse. 1998. Brassinosteroids: Essential regulators of plant growth and development. Annu. Rev. Plant Physiol. Plant Mol. Biol. 49: 427-451.

Cosgrove, D.J. 1994. Photomodulation of growth. In Photomorphogenesis in Plants, 2nd ed. (ed. R.E. Kendrick and G.H.M. Kronenberg), pp. 631-658. Kluwer Academic Publishers, Dordrecht, The Netherlands.

Creelman, R.A. and J.E. Mullet. 1997. Oligosaccharins, brassinolides, and jasmonates: Nontraditional regulators of plant growth, development, and gene expression. Plant Cell 9: 1211-1223.

Davis, S.J., J. Kurepa, and R.D. Vierstra. 1999. The Arabidopsis thaliana HY1 locus, required for phytochrome- chromophore biosynthesis, encodes a protein related to heme oxygenases. Proc. Nat1. Acad. Sci. 96: 6541-6546.

Deng, X.-W. and P. Quail, H. 1999. Signaling in light-controlled development. Cell Dev. Biol. 10: 121-129.

Devlin, P.F., K.J. Halliday, N.P. Harberd, and G.C. Whitelam. 1996. The rosette habit of Arabidopsis thaliana is dependent upon phytochrome action: novel phytochromes control internode elongation and flowering time. Plant J. 10: 11271134.

Devlin, P.F., S.R. Patel, and G.C. Whitelam. 1998. Phytochrome E influences internode elongation and flowering time in Arabidopsis. Plant Cell 10: 1479-1488.

Devlin, P.F., P.R. Robson, S.R. Patel, L. Goosey, R.A. Sharrock, and G.C. Whitelam. 1999. Phytochrome D acts in the shadeavoidance syndrome in Arabidopsis by controlling elongation growth and flowering time. Plant Physiol. 119: 909915.

Dowson-Day, M.J. and A.J. Millar. 1999. Circadian dysfunction causes aberrant hypocotyl elongation patterns in Arabidopsis. Plant I. 17: 63-71.

Elich, T.D. and J. Chory. 1997. Biochemical characterization of Arabidopsis wild-type and mutant phytochrome B holoproteins. Plant Cell 9: 2271-2280.

Ermolayeva, E., H. Hohmeyer, E. Johannes, and D. Sanders. 1996. Calcium-dependent membrane depolarization activated by phytochrome in the moss Physcomitrella patens. Planta 199: 352-358.

Ermolayeva, E., D. Sanders, and E. Johannes. 1997. Ionic mechanism and role of phytochrome-mediated membrane depolarization in caulonemal side branch initial formation in the moss Physcomitrella patens. Planta 201: 109-118.

Fankhauser, C. and J. Chory. 1997. Light control of plant development. Annu. Rev. Cell Dev. Biol. 13: 203-229.

Fankhauser, C., K.C. Yeh, J.C. Lagarias, H. Zhang, T.D. Elich, and J. Chory. 1999. PKS1, a substrate phosphorylated by phytochrome that modulates light signaling in Arabidopsis. Science 284: 1539-1541.

Finlayson, S.A., I.-J. Lee, and P.W. Morgan. 1998. Phytochrome $B$ and the regulation of circadian ethylene production in sorghum. Plant Physiol. 116: 17-25.

Finlayson, S.A., I.-J. Lee, J.E. Mullet, and P.W. Morgan. 1999. The mechanism of rhythmic ethylene production in sorghum. The role of phytochrome B and simulated shading. Plant Physiol. 119: 1083-1089.

Furuya, M. and P.-S. Song. 1994. Assembly and properties of holophytochrome. In Photomorphogenesis in plants, 2nd ed. (ed. R.E. Kendrick and G.H.M. Kronenberg), pp. 105-140. Kluwer Academic Publishers, Dordrecht, The Netherlands.

Garner, W.W. and H.A. Allard. 1920. Effect of the relative length of day and night and other factors of the environment on growth and reproduction in plants. J. Agric. Res. 18: 553606.

Gartner, W., C. Hill, K. Worm, S.E. Braslavsky, and K. Schaffner. 1996. Influence of expression system on chromophore binding and preservation of spectral properties in recombinant phytochrome A. Eur. J. Biochem. 236: 978-983.

Gendreau, E., J. Traas, T. Desnos, O. Grandjean, M. Caboche, and H. Höfte. 1997. Cellular basis of hypocotyl growth in Arabidopsis thaliana. Plant Physiol. 114: 295-305.

Gendreau, E., H. Höfte, O. Grandjean, S. Brown, and J. Traas. 1998. Phytochrome controls the number of endoreduplication cycles in the Arabidopsis thaliana hypocotyl. Plant $T$. 13: $221-230$.

Genoud, T., A.J. Millar, N. Nishizawa, S.A. Kay, E. Schafer, A. Nagatani, and N.-H. Chua. 1998. An Arabidopsis mutant hypersensitive to red and far-red light signals. Plant Cell 10: 889-904.

Goosey, L., L. Palecanda, and R.A. Sharrock. 1997. Differential patterns of expression of the Arabidopsis $P H Y B, P H Y D$, and 
PHYE phytochrome genes. Plant Physiol. 115: 959-969.

Gray, W.M., A. Ostin, G. Sandberg, C.P. Romano, and M. Estelle. 1998. High temperature promotes auxin-mediated hypocotyl elongation in Arabidopsis. Proc. Natl. Acad. Sci. 95: 7197-7202.

Halliday, K.J., M. Koornneef, and G.C. Whitelam. 1994. Phytochrome $\mathrm{B}$, and at least one other phytochrome, mediate the accelerated flowering response of Arabidopsis thaliana L. to low red/far-red ratio. Plant Physiol. 104: 1311-1315.

Halliday, K.J., B. Thomas, and G.C. Whitelam. 1997. Expression of heterologous phytochromes A, B or C in transgenic tobacco plants alters vegetative development and flowering time. Plant I. 12: 1079-1090.

Halliday, K.J., M. Hudson, M. Ni, M. Qin, and P.H. Quail. 1999. poc1: An Arabidopsis mutant perturbed in phytochrome signaling because of a T-DNA insertion in the promoter of PIF3, a gene encoding a phytochrome-interacting bHLH protein. Proc. Nat1. Acad. Sci. 96: 5832-5837.

Hamada, T., N. Tanaka, T. Noguchi, N. Kimura, and K. Hasunuma. 1996. Phytochrome regulates phosphorylation of a protein with characteristics of a nucleoside diphosphate kinase in the crude membrane fraction from stem sections of etiolated pea seedlings. J. Photochem. Photobiol. B. 33: 143151.

Hamazato, F., T. Shinomura, H. Hanzawa, J. Chory, and M. Furuya. 1997. Fluence and wavelength requirements for Arabidopsis $\mathrm{CAB}$ gene induction by different phytochromes. Plant Physiol 115: 1533-1540.

Hangarter, R.P. 1997. Gravity, light and plant form. Plant Cell Environ. 20: 796-800.

Harris, R.A., J.W. Hawes, K.M. Popov, Y. Zhao, Y. Shimomura, J. Sato, J. Jaskiewicz, and T.D. Hurley. 1997. Studies on the regulation of the mitochondrial alpha-ketoacid dehydrogenase complexes and their kinases. Adv. Enz. Reg. 37: 271293.

Haupt, W. and D.P. Häder. 1994. Photomovement. In Photomorphogenesis in plants, 2nd ed. (ed. R.E. Kendrick and G.H.M. Kronenberg), pp. 707-732. Kluwer Academic Publishers, Dordrecht, The Netherlands.

Hayami, J., A. Kadota, and M. Wada. 1986. Blue light-induced phototropic response and the intracellular photoreceptive site in Adiantum protonema. Plant Cell Physiol. 27: 15711577.

Hennig, L., C. Poppe, S. Unger, and E. Schafer. 1999. Control of hypocotyl elongation in Arabidopsis thaliana by photoreceptor interaction. Planta 208: 257-263.

Hicks, K., A. Millar, I. Carr, D. Somers, M. Straume, D.R. Meeks-Wagner, and S. Kay. 1996. Conditional circadian dysfunction of the Arabidopsis early-flowering 3 mutant. Science 274: 790-792.

Hirschfeld, M., J.M. Tepperman, T. Clack, P.H. Quail, and R.A. Sharrock. 1998. Coordination of phytochrome levels in phyB mutants of Arabidopsis as revealed by apoprotein-specific monoclonal antibodies. Genetics 149: 523-535.

Hoecker, U., Y. Xu, and P.H. Quail. 1998. SPA1: A new genetic locus involved in phytochrome A-specific signal transduction. Plant Cell 10: 19-33.

Hoecker, U., J.M. Tepperman, and P.H. Quail. 1999. SPA1, a WD-repeat protein specific to phytochrome A signal transduction. Science 284: 496-499.

Huang, Z.J., I. Edery, and M. Rosbash. 1993. Pas is a dimerization domain common to Drosophila period and several transcription factors. Nature 364: 259-262.

Hudson, M., C. Ringli, M.T. Boylan, and P.H. Quail. 1999. The FAR1 locus encodes a novel nuclear protein specific to phytochrome A signaling. Genes \& Dev. 13: 2017-2027.
Hughes, J., T. Lamparter, F. Mittman, E. Hartmann, W. Gärtner, A. Wilde, and T. Börner. 1997. A prokaryotic phytochrome. Nature 386: 663.

Jackson, S.D., A. Heyer, J. Dietze, and S. Prat. 1996. Phytochrome B mediates the photoperiodic control of tuber formation in potato. Plant J. 9: 159-166.

Jackson, S.D., P. James, S. Prat, and B. Thomas. 1998. Phytochrome B affects the levels of a graft-transmissible signal involved in tuberization. Plant Physiol. 117: 29-32.

Jacobsen, S.E. and N.E. Olszewski. 1993. Mutations at the SPINDLY locus of Arabidopsis alter gibberellin signal transduction. Plant Cell 5: 887-896.

Jaffe, M.J. 1968. Phytochrome-mediated bioelectric potentials in Mung bean seedlings. Science 162: 1016-1017.

Janoudi, A.K., W.R. Gordon, D. Wagner, P. Quail, and K.L. Poff. 1997. Multiple phytochromes are involved in red-light-induced enhancement of first-positive phototropism in Arabidopsis thaliana. Plant Physiol. 113: 975-979.

Jensen, P.J., R.P. Hangarter, and M. Estelle. 1998. Auxin transport is required for hypocotyl elongation in light-grown but not dark-grown Arabidopsis. Plant Physiol. 116: 455-462.

Kamiya, Y. and J.L. Garcìa-Martìnez. 1999. Regulation of gibberellin biosynthesis by light. Curr. Opin. Plant Biol. 2: 398403.

Kay, S.A. 1997. PAS, present, and future: clues to the origins of circadian clocks. Science 276: 753-754.

Kehoe, D.M. and A.R. Grossman. 1996. Sensor of chromatic adaptation is similar to phytochrome and ethylene receptors. Science 273: 1409-1412.

Kende, H. and J.A.D. Zeevart. 1997. The five "classical" plant hormones. Plant Cell 9: 1197-1210.

Kendrick, R.E. and M.E. Bossen. 1987. Photocontrol of ion fluxes and membrane properties in plants. In Phytochrome and photoregulation in plants (ed. M. Furuya), pp. 215-224. Academic Press, Tokyo, Japan.

Kendrick, R.E. and G.H.M. Kronenberg. 1994. Photomorphogenesis in plants 2nd ed. Kluwer Academic Publishers, Dordrecht, The Netherlands.

Kim, B.C., M.S. Soh, S.H. Hong, M. Furuya, and H.G. Nam. 1998. Photomorphogenic development of the Arabidopsis shy2-1D mutation and its interaction with phytochromes in darkness. Plant J. 15: 61-68.

Kircher, S., L. Kozma-Bognar, L. Kim, E. Adam, K. Harter, E. Schafer, and F. Nagy. 1999. Light quality-dependent nuclear import of the plant photoreceptors phytochrome A and B. Plant Cell 11: 1445-1456.

Komeili, A. and E.K. O'Shea. 1999. Roles of phosphorylation sites in regulating activity of the transcription factor Pho4. Science 284: 977-980.

Koornneef, M., E. Rolff, and C.J.P. Spruit. 1980. Genetic control of light-inhibited hypocotyl elongation in Arabidopsis thaliana (L.). Heynh. Z. Pflanzenphysiol. 100S: 147-160

Kunkel, T., G. Neuhaus, A. Batschauer, N.-H. Chua, and E. Schäfer. 1996. Functional analysis of yeast-derived phytochrome A and B phycocyanobilin adducts. Plant J. 10: 625636.

Kuno, M., T. Muramatsu, F. Hamazato, and M. Furuya. 2000. Identification by large-scale screening of phytochrome regulated genes in etiolated seedlings of Arabidopsis thaliana using a fluorescent differential display technique. Plant Physiol. 122: 15-24.

Lagarias, D.M., S.-H. Wu, and J.C. Lagarias. 1995. Atypical phytochrome gene structure in the green alga Mesotaenium caldariorum. Plant Mol. Biol. 29: 1127-1142.

Lagarias, J.C. and H. Rapoport. 1980. Chromopeptides from phytochrome. The structure and linkage of the Pr form of the 
phytochrome chromophore. J. Am. Chem. Soc. 102: 48214828.

Lamond, A.I. and W.C. Earnshaw. 1998. Structure and function in the nucleus. Science 280: 547-553.

Lamparter, T., F. Mittmann, W. Gartner, T. Borner, E. Hartmann, and J. Hughes. 1997. Characterization of recombinant phytochrome from the cyanobacterium Synechocystis. Proc. Natl. Acad. Sci. 94: 11792-11797.

Lapko, V.N., X.Y. Jiang, D.L. Smith, and P.-S. Song. 1997. Posttranslational modification of oat phytochrome A: phosphorylation of a specific serine in a multiple serine cluster. Biochemistry 36: 10595-10599.

Lapko, V.N., X.-Y. Jiang, D.L. Smith, and P.-S. Song. 1999. Mass spectroscopic characterization of oat phytochrome A: isoforms and post-translational modifications. Protein Sci. 8: 111.

Li, J. and J. Chory. 1999. Brassinosteroid actions in plants. J. Exp. Bot. 50: 275-282.

Lissemore, J.L. and P.H. Quail. 1988. Rapid transcriptional regulation by phytochrome of the genes for phytochrome and chlorophyll a/b-binding protein in Avena sativa. Mol. Cell Biol. 8: 4840-4850.

Mathews, S. and M.J. Donoghue. 1999. The root of angiosperm phylogeny inferred from duplicate phytochrome genes. Science 286: 947-950.

Mathews, S. and R.A. Sharrock. 1997. Phytochrome gene diversity. Plant Cell Environ. 20: 666-671.

Mancinelli, A.L. 1994. The physiology of phytochrome actions. In Photomorphogenesis in plants, 2nd ed. (ed. R.E. Kendrick and G.H.M. Kronenberg), pp. 211-270. Kluwer Academic Publishers, Dordrecht, The Netherlands.

McGrath, R.B. and J.R. Ecker. 1998. Ethylene signaling in Arabidopsis: Events from the membrane to the nucleus. Plant Physiol. Biochem. 36: 103-113.

Millar, A., M. Straume, J. Chory, N.-H. Chua, and S. Kay. 1995. The regulation or circadian period by phototransduction pathways in Arabidopsis. Science 267: 1163-1166.

Mockler, T.C., H. Guo, H. Yang, H. Duong, and C. Lin. 1999. Antagonistic actions of Arabidopsis cryptochromes and phytochrome B in the regulation of floral induction. Development 126: 2073-2082.

Mohr, H. 1994. Coaction between pigment systems. In Photomorphogenesis in Plants, 2nd ed. (ed. R.E. Kendrick and G.H.M. Kronenberg), pp. 353-376. Kluwer Academic Publishers, Dordrecht, The Netherlands.

Muramoto, T., T. Kohchi, A. Yokota, I. Hwang, and H.M. Goodman. 1999. The Arabidopsis photomorphogenic mutant hyl is deficient in phytochrome chromophore biosynthesis as a result of a mutation in a plastid heme oxygenase. Plant Cell 11: 335-348.

Murphy, J.T. and J.C. Lagarias. 1997. The phytofluors: a new class of fluorescent protein probes. Curr. Biol. 7: 870-876.

Mustilli, A.C. and C. Bowler. 1997. Tuning in to the signals controlling photoregulated gene expression in plants. EMBO. J. 16: $5801-5806$.

Neff, M.M. and J. Chory. 1998. Genetic interactions between phytochrome A, phytochrome B, and cryptochrome 1 during Arabidopsis development. Plant Physiol. 118: 27-35.

Neff, M.M. and E. Van Volkenburgh. 1994. Light-stimulated cotyledon expansion in Arabidopsis seedlings. Plant Physiol. 104: 1027-1032.

Neff, M.M., S.M. Nguyen, E.J. Malancharuvil, S. Fujioka, T. Noguchi, H. Seto, M. Tsubuki, T. Honda, S. Takasuto, S. Yoshida and J. Chory. 1999. BAS1: A gene regulating brassinosteroid levels and light responsiveness in Arabidopsis. Proc. Nat1. Acad. Sci. 96: 15316-15323.
Neuhaus, G., C. Bowler, R. Kern, and N.-H. Chua. 1993. Calcium/calmodulin-dependent and -independent phytochrome signal transduction pathways. Cell 73: 937-952.

Neuhaus, G., C. Bowler, K. Hiratsuka, H. Yamagata, and N.-H. Chua. 1997. Phytochrome-regulated repression of gene expression requires calcium and cGMP. EMBO. I. 16: 25542564.

Ni, M., J.M. Tepperman, and P.H. Quail. 1998. PIF3, a phytochrome-interacting factor necessary for normal photoinduced signal transduction, is a novel basic helix-loop-helix protein. Cell 95: 657-667.

Ni, M., J.M. Tepperman, and P.H. Quail. 1999. Binding of phytochrome B to its nuclear signalling partner PIF3 is reversibly induced by light. Nature 400: 781-784.

Nozue, K., T. Kanegae, T. Imaizumi, S. Fukuda, H. Okamoto, K.C. Yeh, J.C. Lagarias, and M. Wada. 1998. A phytochrome from the fern Adiantum with features of the putative photoreceptor NPH1. Proc. Nat1. Acad. Sci. 95: 15826-15830.

Ogura, T., N. Tanaka, N. Yabe, S. Komatsu, and K. Hasunuma. 1999. Characterization of protein complexes containing nucleoside diphosphate kinase with characteristics of light signal transduction through phytochrome in etiolated pea seedlings. Photochem. Photobiol. 69: 397-403.

Olsen, J.E., O. Junttila, J. Nielsen, M.E. Eriksson, I. Martinussen, O. Olsson, G. Sandberg, and T. Moritz. 1997. Ectopic expression of oat phytochrome A in hybrid aspen changes critical daylength for growth and prevents cold acclimatization. Plant J. 12: 1339-1350.

Osterlund, M.T., L.H. Ang, and X.-W. Deng. 1999. The role of COP1 in repression of Arabidopsis photomorphogenic development. Trends Cell Biol. 9: 113-118.

Oyama, T., Y. Shimura, and K. Okada. 1997. The Arabidopsis HY5 gene encodes a bZIP protein that regulates stimulusinduced development of root and hypocotyl. Genes \& Dev. 11: 2983-2995.

Parks, B.M., P.H. Quail, and R.P. Hangarter. 1996. Phytochrome A regulates red-light induction of phototropic enhancement in Arabidopsis. Plant Physiol. 110: 155-162.

Pratt, L.H. 1994. Distribution and localization of phytochrome within the plant. In Photomorphogenesis in plants, 2nd ed. (ed. R.E. Kendrick and G.H.M. Kronenberg), pp. 163-186. Kluwer Academic Publishers, Dordrecht, The Netherlands.

Qin, M., R. Kuhn, S. Moran, and P.H. Quail. 1997. Overexpressed phytochrome $\mathrm{C}$ has similar photosensory specificity to phytochrome B but a distinctive capacity to enhance primary leaf expansion. Plant J. 12: 1163-1172.

Quail, P.H. 1997. An emerging molecular map of the phytochromes. Plant Cell Environ. 20: 657-665.

Quail, P.H., M.T. Boylan, B.M. Parks, T.W. Short, Y. Xu, and D. Wagner. 1995. Phytochromes: Photosensory perception and signal transduction. Science 268: 675-680.

Racusen, R.H. and A.W. Galston. 1983. Developmental significance of light-mediated electrical responses in plant tissue. In Photomorphogenesis (ed. W. Shropshire Jr. and H. Mohr), pp. 687-703. Springer-Verlag, Berlin, Germany.

Reed, J.W., P. Nagpal, D.S. Poole, M. Furuya, and J. Chory. 1993. Mutations in the gene for the red/far red light receptor phytochrome B alter cell elongation and physiological responses throughout Arabidopsis development. Plant Cell 5: 147-157.

Reed, J.W., A. Nagatani, T.D. Elich, M. Fagan, and J. Chory. 1994. Phytochrome A and Phytochrome B have overlapping but distinct functions in Arabidopsis development. Plant Physiol. 104: 1039-1049.

Reed, J.W., R.P. Elumalai, and J. Chory. 1998. Suppressors of an Arabidopsis thaliana phyB mutation identify genes that control light signaling and hypocotyl elongation. Genetics 
148: $1295-1310$.

Remberg, A., A. Ruddat, S.E. Braslavsky, W. Gartner, and K. Schaffner. 1998. Chromophore incorporation, Pr to Pfr kinetics, and Pfr thermal reversion of recombinant $\mathrm{N}$-terminal fragments of phytochrome A and B chromoproteins. Biochemistry 37: 9983-9990.

Robson, P.R.H. and H. Smith. 1997. Fundamental and biotechnological applications of phytochrome transgenes. Plant Cell Environ. 20: 831-839.

Robson, P.R.H., G.C. Whitelam, and H. Smith. 1993. Selected components of the shade-avoidance syndrome are displayed in a normal manner in mutants of Arabidopsis thaliana and Brassica rapa deficient in Phytochrome B. Plant Physiol. 102: 1179-1184.

Robson, P.R.H., A.C. McCormac, A.S. Irvine, and H. Smith. 1996. Genetic engineering of harvest index in tobacco through overexpression of a phytochrome gene. Nature Biotechnol. 14: 995-998.

Romano, C.P., P.R.H. Robson, H. Smith, M. Estelle, and H. Klee. 1995. Transgene-mediated auxin overproduction in Arabidopsis: hypocotyl elongation phenotype and interactions with the hy6-1 hypocotyl elongation and axr1 auxinresistant mutants. Plant Mol. Biol. 27: 1071-1083.

Roux, S.J. 1994. Signal transduction in phytochrome responses. In Photomorphogenesis in plants, 2nd ed. (ed. R.E. Kendrick and G.H.M. Kronenberg), pp. 187-209. Kluwer Academic Publishers, Dordrecht, The Netherlands.

Sage, L.C. 1992. Pigment of the imagination: A history of phytochrome research. Academic Press, San Diego, CA.

Sakamoto, K. and A. Nagatani. 1996. Nuclear localization activity of phytochrome B. Plant J. 10: 859-868.

Schaffer, R., N. Ramsay, A. Samach, S. Corden, J. Putterill, I.A. Carre, and G. Coupland. 1998. The late elongated hypocotyl mutation of Arabidopsis disrupts circadian rhythms and the photoperiodic control of flowering. Cell 93: 1219-1229.

Schena, M., A.M. Lloyd, and R.W. Davis. 1993. The HAT4 gene of Arabidopsis encodes a developmental regulator. Genes \& Dev. 7: 367-379.

Schneider-Poetsch, H.A.W. 1992. Signal transduction by phytochrome: phytochromes have a module related to the transmitter modules of bacterial sensor proteins. Photochem. Photobiol. 56: 839-846.

Serlin, B.S. and S.J. Roux. 1984. Modulation of chloroplast movement in the green alga Mougeotia by the Ca++ ionophore A23187 and by calmodulin antagonists. Proc. Nat1. Acad. Sci. 81: 6368-6372.

Serlin, B.S., R.R. Lew, F. Krasnoshtein, J. Krol, and K.D. Sumida. 1996. Phytochrome activation of K+ channels and chloroplast rotation in Mougeotia: The escape times. Plant Cell Physiol. 37: 175-179.

Shacklock, P.S., N.D. Read, and A.J. Trewavas. 1992. Cytosolic free calcium mediates red light-induced photomorphogenesis. Nature 358: 753-755.

Sharrock, R.A. and P.H. Quail. 1989. Novel phytochrome sequences in Arabidopsis thaliana: Structure, evolution, and differential expression of a plant regulatory photoreceptor family. Gene \& Dev. 3: 1745-1757.

Shinomura, T., A. Nagatani, J. Chory, and M. Furuya. 1994. The induction of seed germination in Arabidopsis thaliana is regulated principally by phytochrome $B$ and secondarily by phytochrome A. Plant Physiol. 104: 363-371.

Shinomura, T., A. Nagatani, H. Hanzawa, M. Kubota, M. Watanabe, and M. Furuya. 1996. Action spectra for phytochrome A- and B-specific photoinduction of seed germination in Arabidopsis thaliana. Proc. Nat1. Acad. Sci. 93: 8129-8133.
Shinomura, T., K. Uchida, and M. Furuya. 2000. Elementary responses of photoperception by phytochrome A for high irradiance response of hypocotyl elongation in Arabidopsis thaliana. Plant Physiol. 122: 147-156.

Shropshire, W. and H. Mohr. 1970. Gradient formation of anthocyanin in seedlings of Fagopyrum and Sinapis unilaterally exposed to red and far-red light. Photochem. Photobiol. 12: $145-149$.

Smith, H. 1994. Sensing the light environment: the functions of the phytochrome family. In Photomorphogenesis in plants, 2nd ed. (ed. R.E. Kendrick and G.H.M. Kronenberg), pp. 377416. Kluwer Academic Publishers, Dordrecht, The Netherlands.

1995. Physiological and ecological function within the phytochrome family. Annu. Rev. Plant Physiol. Plant Mol. Biol. 46: 289-315.

- 1999. Phytochromes. Tripping the light fantastic. Nature 400: 710-711, 713.

Smith, H. and G.C. Whitelam. 1997. The shade avoidance syndrome: Multiple responses mediated by multiple phytochromes. Plant Cell Environ. 20: 840-844.

Soh, M.S., S.H. Hong, H. Hanzawa, M. Furuya, and H.G. Nam. 1998. Genetic identification of FIN2, a far red light-specific signaling component of Arabidopsis thaliana. Plant I. 16: 411-419.

Somers, D.E. and P.H. Quail. 1995a. Phytochrome-mediated light regulation of $P H Y A$ - and $P H Y B-G U S$ transgenes in Arabidopsis thaliana seedlings. Plant Physiol. 107: 523-534.

- 1995b. Temporal and spatial expression patterns of PHYA and PHYB genes in Arabidopsis. Plant J. 7: 413-427.

Somers, D.E., P.F. Devlin, and S.A. Kay. 1998. Phytochromes and cryptochromes in the entrainment of the Arabidopsis circadian clock. Science 282: 1488-1490.

Spalding, E.P. and M.H.M. Goldsmith. 1993. Activation of $\mathrm{K}^{+}$ channels in the plasma membrane of Arabidopsis by ATP produced photosynthetically. Plant Cell 5: 477-484.

Steindler, C., A. Matteucci, G. Sessa, T. Weimar, M. Ohgishi, T. Aoyama, G. Morelli, and I. Ruberti. 1999. Shade avoidance responses are mediated by the ATHB-2 HD-Zip protein, a negative regulator of gene expression. Development 126: 4235-4245.

Stockhaus, J., A. Nagatani, U. Halfter, S. Kay, M. Furuya, and N.-H. Chua. 1992. Serine-to-alanine substitutions at the amino-terminal region of phytochrome A result in an increase in biological activity. Genes \& Dev. 6: 2364-2372.

Sugano, S., C. Andronis, R.M. Green, Z.Y. Wang, and E.M. Tobin. 1998. Protein kinase CK2 interacts with and phosphorylates the Arabidopsis circadian clock-associated 1 protein. Proc. Nat1. Acad. Sci. 95: 11020-11025.

Sugano, S., C. Andronis, M.S. Ong, R.M. Green, and E.M. Tobin. 1999. The protein kinase CK2 is involved in regulation of circadian rhythms in Arabidopsis. Proc. Natl. Acad. Sci. 96: 2362-12366.

Tanada, T. 1967. A rapid photoreversible response of barley root tips in the presence of 3 -indoleacetic acid. Proc. Natl. Acad. Sci. 59: 376-380.

- 1968. Short communication: Substances essential for a red, far-red light reversible attachment of mung bean root tips to glass. Plant Physiol. 43: 2070-2071.

Tanaka, N., T. Ogura, T. Noguchi, H. Hirano, N. Yabe, and K. Hasunuma. 1998. Phytochrome-mediated light signals are transduced to nucleoside diphosphate kinase in Pisum sativum L. cv. Alaska. J. Photochem. Photobiol. B. 45: 113121.

Taylor, B.L. and I.B. Zhulin. 1999. PAS domains: internal sensors of oxygen, redox potential, and light. Microbiol. Mol. 
Biol. Rev. 63: 479-506.

Tazawa, M. and T. Shimmen. 1980. Direct demonstration of the involvement of chloroplasts in the rapid light-induced potential change in tonoplast-free cells of Chara australis. Replacement of Chara chloroplasts with spinach chloroplasts. Plant Cell Physiol. 21: 1527-1534.

Terry, M.J. 1997. Phytochrome chromophore-deficient mutants. Plant Cell Envirno. 20: 740-745.

Thiele, A., M. Herold, I. Lenk, P.H. Quail, and C. Gatz. 1999. Heterologous expression of Arabidopsis phytochrome B in transgenic potato influences photosynthetic performance and tuber development. Plant Physiol. 120: 73-82.

Tian, Q. and J.W. Reed. 1999. Control of auxin-regulated root development by the Arabidopsis thaliana SHY2/IAA3 gene. Development 126: 711-721.

Tretyn, A., R.E. Kendrick, and M.E. Bossen. 1990. The effect of a calcium-channel antagonist, nifedipine and agonist Bay $\mathrm{K}-8644$, on the phytochrome-controlled swelling of etiolated wheat protoplasts. Physiol. Plant 78: 230-235.

Vince-Prue, D. 1994. The duration of light and photoperiodic responses. In Photomorphogenesis in plants, - 2nd edition. (ed. R.E. Kendrick and G.H.M. Kronenberg), pp. 447-490. Kluwer Academic Publishers, Dordrecht, The Netherlands.

Wagner, D., J.M. Tepperman, and P.H. Quail. 1991. Overexpression of phytochrome B induces a short hypocotyl phenotype in transgenic Arabidopsis. Plant Cell 3: 1275-1288.

Wagner, D., U. Hoecker, and P.H. Quail. 1997. RED1 is necessary for phytochrome B-mediated red light-specific signal transduction in Arabidopsis. Plant Cell 9: 731-743.

Wang, X. and M. Iino. 1998. Interaction of cryptochrome 1, phytochrome, and ion fluxes in blue- light-induced shrinking of Arabidopsis hypocotyl protoplasts. Plant Physiol. 117: 12651279.

Wang, Z.Y. and E.M. Tobin. 1998. Constitutive expression of the CIRCADIAN CLOCK ASSOCIATED 1 (CCA1) gene disrupts circadian rhythms and suppresses its own expression. Cell 93: 1207-1217.

Wayne, R. and P.K. Hepler. 1984. The role of calcium ions in phytochrome-mediated germination of spores of Onoclea sensibilis L. Planta 160: 12-20.

Wei, N. and X.-W. Deng. 1999. Making sense of the COP9 signalosome. A regulatory protein complex conserved from Arabidopsis to human. Trends Genet. 15: 98-103.

Weisenseel, M.H. and H.K. Ruppert. 1977. Phytochrome and calcium ions are involved in light-induced membrane depolarization in Nitella. Planta 137: 225-229.

Whitelam, G.C. and P.F. Devlin. 1997. Roles of different phytochromes in Arabidopsis photomorphogenesis. Plant Cell Environ. 20: 752-758.

Whitelam, G.C. and H. Smith. 1991. Retention of phytochromemediated shade avoidance responses in phytochrome-deficient mutants of Arabidopsis, cucumber and tomato. J. Plant Physiol. 139: 119-125.

Whitelam, G.C., E. Johnson, J. Peng, P. Carol, M.L. Anderson, J.S. Cowl, and N.P. Harberd. 1993. Phytochrome A null mutants of Arabidopsis display a wild-type phenotype in white light. Plant Cell 5: 757-768.

Woitzik, F. and H. Mohr. 1988. Control of hypocotyl phototropism by phytochrome in a dicotyledonous seedling (Sesamum indicum L.). Plant Cell Environ. 11: 653-661.

Wong, Y.-S., H.-C. Cheng, D.A. Walsh, and J.C. Lagarias. 1986. Phosphorylation of Avena phytochrome in vitro as a probe of light-induced conformational changes. J. Biol. Chem. 261: 12089-12097.

Yamaguchi, R., M. Nakamura, N. Mochizuki, S.A. Kay, and A. Nagatani. 1999. Light-dependent translocation of a phyto- chrome B-GFP fusion protein to the nucleus in transgenic Arabidopsis. J. Cell Biol. 145: 437-445.

Yeh, K.C. and J.C. Lagarias. 1998. Eukaryotic phytochromes: light-regulated serine/threonine protein kinases with histidine kinase ancestry. Proc. Natl. Acad. Sci. 95: 13976-13981.

Yeh, K.C., S.H. Wu, J.T. Murphy, and J.C. Lagarias. 1997. A cyanobacterial phytochrome two-component light sensory system. Science 277: 1505-1508.

Yunghans, H. and M.J. Jaffe. 1970. Phytochrome controlled adhesion of Mung bean root tips to glass: A detailed characterization of the phenomenon. Physiol. Plant. 23: 1004-1016. 


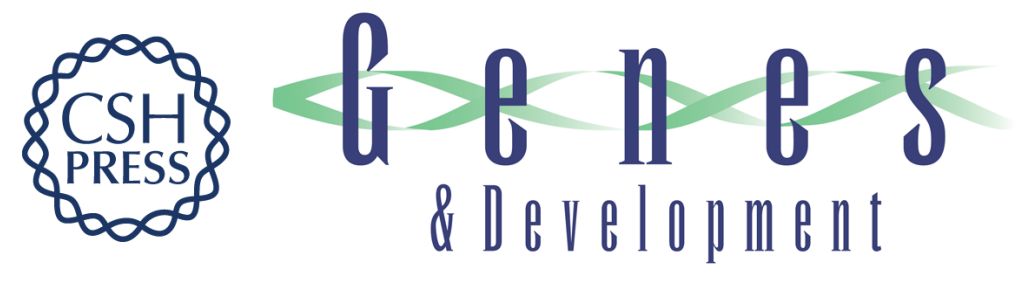

\section{Light: an indicator of time and place}

Michael M. Neff, Christian Fankhauser and Joanne Chory

Genes Dev. 2000, 14:

Access the most recent version at doi:10.1101/gad.14.3.257

References This article cites 163 articles, 82 of which can be accessed free at: http://genesdev.cshlp.org/content/14/3/257.full.html\#ref-list-1

License

Email Alerting Receive free email alerts when new articles cite this article - sign up in the box at the top Service right corner of the article or click here.

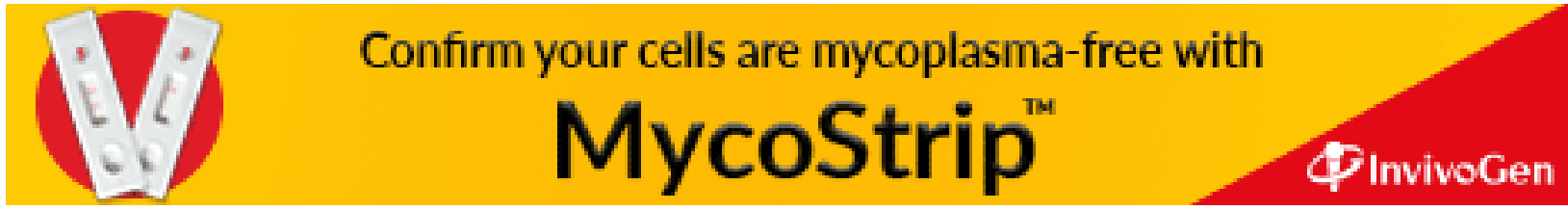

